\title{
The Catalytic Properties of Gold
}

\section{POTENTIAL APPLIGATIONS IN THE CHEMICAL INDUSTRY}

\author{
Professor G. C. Bond \\ Brunel University, Uxbridge, Middlesex, England
}

\begin{abstract}
Although the catalytic properties of gold are surpassed by those of the Group VIII metals, especially palladium and platinum, possible applications of gold in catalytic processes have been widely studied, more especially for oxidative dehydrogenation. Alloys and mixtures of gold with the platinum group metals are also receiving increased attention, and the developments outlined here indicate a number of potential uses.
\end{abstract}

The chemical inertness of gold, a diamagnetic metal of extreme nobility, would appear at first sight to render it unsuitable as a catalyst, since catalysis requires the formation at the surface of intermediate species of moderate stability. This expectation is well supported by experience. Gold adsorbs neither hydrogen (1) nor oxygen (2) to any significant extent at ambient temperatures and it cannot therefore act as a hydrogenation or oxidation catalyst in the normal sense. Notwithstanding this unfavourable prognosis, by means of certain procedures conceived by those skilled in the art, gold has been shown to have some most interesting properties.

\section{Reactivity of Hydrogen on Gold Surfaces}

Although gold surfaces do not chemisorb molecular hydrogen at room temperature, sufficient chemisorption with the formation of atomic hydrogen occurs above about $200^{\circ} \mathrm{C}$ for the hydrogen equilibration reactions

$$
\begin{aligned}
& \mathrm{H}_{2}+\mathrm{D}_{2} \rightarrow 2 \mathrm{HD} \\
& \text { and } p-\mathrm{H}_{2} \rightarrow o-\mathrm{H}_{2}
\end{aligned}
$$

to be readily studied (3). The surface coverages are nevertheless probably quite small and the activity of gold is similar to that of silver and copper (4). The following interpretation of these observations has been advanced. The inability of gold (and silver) to interact with molecular hydrogen is due to its lack of essential unpaired $d$-electrons; however, thermal energy at about $200^{\circ} \mathrm{C}$ is sufficient to excite a few $5 d$-electrons into the $6 s$ level, thus fulfilling the necessary criterion.

A gold surface will chemisorb hydrogen atoms (albeit weakly) if they are supplied as such, for example through atomisation of molecular hydrogen in an electric discharge. The atoms are mobile but unstable, and for this reason gold is quite an active catalyst for the recombination of hydrogen atoms (5), viz.

$$
2 \mathrm{H}-\mathrm{Au} \rightarrow \mathrm{H}_{2}+2 \mathrm{Au}
$$

Perhaps of greater interest is the ability of gold to abstract hydrogen atoms from a hydrogencontaining organic molecule. An excellent example of this is the ability of gold to catalyse the decomposition of formic acid:

$$
\mathrm{HCOOH} \rightarrow \mathrm{H}_{2}+\mathrm{CO}_{2}
$$

We need not concern ourselves with the detailed mechanism (6), but adsorbed hydrogen atoms are certainly intermediates. For example, they react rapidly with oxygen to form water, although the molecular reaction

$$
2 \mathrm{H}_{2}+\mathrm{O}_{2} \rightarrow 2 \mathrm{H}_{2} \mathrm{O}
$$

only occurs slowly at the same temperature (6). This is the basis of oxidative dehydrogenation discussed below. Hydrogen atoms are abstracted from hydrocarbons such as cyclohexane above $200^{\circ} \mathrm{C}(7)$.

An ingenious way of forming hydrogen atoms on gold has been described by Wood and Wise (8). The outer surface of a palladium-silver diffusion thimble was electroplated with gold, and molecular hydrogen supplied to the inside. Hydrogen atoms diffused through the palladium-silver alloy and through the gold, and emerged at the gold surface where they were shown to be capable of reacting with alkenes (e.g. cyclohexene) to form the corresponding alkane. The reaction occurs above about $100^{\circ} \mathrm{C}$, and in this way gold can be persuaded to act as a hydrogenation catalyst.

\section{Oxidative Dehydrogenation}

Although the patent literature is replete with claims for the ability of gold to act as a catalyst, there is no firm indication as yet of any commercial 
process using gold per se. However, there are a number of interesting claims concerning oxidative dehydrogenation, which can be formalised as

$$
\mathrm{AH}_{2} \rightleftharpoons \mathrm{A}+\mathrm{H}_{2} ; \mathrm{H}_{2}+\frac{1}{2} \mathrm{O}_{2} \rightarrow \mathrm{H}_{2} \mathrm{O}
$$

where $A$ is the dehydrogenated organic molecule. The role of the oxygen is clearly to move the equilibrium to the right, and since oxygen is at most only weakly adsorbed on gold there is no catalysis of the deep oxidation of the molecule $\mathrm{AH}_{2}$ (i.e. to carbon dioxide).

Examples quoted in the patent literature include the dehydrogenation of cyclohexanone to cyclohexenone (9), of ethyleneglycol to glyoxal (10):

$$
\mathrm{HOCH}_{2}-\mathrm{CH}_{2} \mathrm{OH} \rightarrow \mathrm{OHC}-\mathrm{CHO}+2 \mathrm{H}_{2}
$$

and of ethylpyridine to vinylpyridine (11). The mechanism of the dehydrogenation of methanol to formaldehyde has been studied on a gold wire (12), and there are indications that gold may be more selective than silver in the commercially important oxidative process

$$
\mathrm{CH}_{3} \mathrm{OH}+\frac{1}{2} \mathrm{O}_{2} \rightarrow \mathrm{HCHO}+\mathrm{H}_{2} \mathrm{O} \text {. }
$$

\section{Isomerisation of Hydrocarbons}

It has been recognised for some years that platinum is able by itself and in the absence of an acidic support to effect skeletal isomerisation of hydrocarbons to more highly branched hydrocarbons, for example, of hexane to isohexane:

$$
\mathrm{C}-\mathrm{C}-\mathrm{C}-\mathrm{C}-\mathrm{C}-\mathrm{C} \rightarrow \mathrm{C}-\underset{\mathrm{C}}{\mathrm{C}}-\mathrm{C}-\mathrm{C}-\mathrm{C}
$$

It is not really understood to what extent this accounts for the use of platinum in petroleum reforming catalysts, but it is of interest to note a recent survey of a number of metals which shows that only iridium and gold besides platinum possess this property (13). It must be more than a coincidence that these three metals are adjacent in the third transition series, and that palladium and silver, for example, lack this facility. Gold is far less active than iridium and platinum; but, as Dr. Johnson remarked in another context, "It is not done well; but you are surprised to find it done at all".

\section{Gold as a Component of Noble Metal Catalysts}

Quite the most important catalytic application of gold at the present time is in conjunction with other more active metals of the platinum group. This conjunction can take one of two forms. Either gold is alloyed with the other metal, or it is simply physically admixed with it in the catalyst.

A great deal of academic work has been carried out over the past twenty years on alloy catalysts, especially on palladium-gold alloys (14). This system has been favoured because it forms a continuous range of solid solutions, unlike the platinumgold system, which exhibits a miscibility gap. Unfortunately most of this work has been done with alloys in the form of wire or foil or evaporated film, none of which are at all suited to large-scale industrial use, and only recently has attention been given to the preparation and characterisation of supported alloys. Most of this work has been directed to examining the role of the unpaired $d$-electrons, since these become completely paired in alloys containing about 60 atomic per cent gold.

We need not concern ourselves deeply with the results of all this work, and will only note that in most cases the catalytic activity decreases on addition of gold to palladium: however, in a few rare instances the activity of the alloy containing about 80 per cent palladium-20 per cent gold is somewhat more than that of pure palladium (14).

Although the patent literature makes numerous references to multicomponent metal catalysts, it is only rarely specified whether they are alloyed or only physically mixed. It is, however, well established that mixtures of metals can act synergistically, i.e., can show an activity greater than the sum of their separate activities.

One application in which gold is frequently mentioned is as an addition to silver in connection with the catalytic oxidation of ethylene to ethylene oxide (15). There is some improvement in selectivity (i.e., less carbon dioxide formation) but activity is diminished as a consequence of the addition of gold.

There are very many patent references to palladium with gold on a support as a catalyst for the synthesis of vinyl acetate from ethylene, oxygen and acetic $\operatorname{acid}(16)$ :

$$
\begin{array}{r}
\mathrm{C}_{2} \mathrm{H}_{4}-\frac{1}{2} \mathrm{O}_{2}+\mathrm{CH}_{3} \mathrm{COOH} \rightarrow \\
\mathrm{CH}_{3} \mathrm{COOC}_{2} \mathrm{H}_{3} \div \mathrm{H}_{2} \mathrm{O}
\end{array}
$$

This process operates commercially in the United States and will shortly do so in Great Britain. The part which the gold plays is uncertain, but some patents describe a preparative method involving hydrazine as reductant. The procedures described have been studied in the author's department. X-ray diffraction measurements show that alloys are formed under varied preparative conditions, but that the use of hydrogen as reductant does not lead to alloy formation (17).

\section{Conclusion}

The chief areas of application of gold as a catalyst seem at the moment to be in oxidative dehydrogenation and as an addition to silver or palladium for 
selective oxidation processes. There is, however, reason to hope that repair of the neglect which gold has suffered in the past will generate new and exciting applications for this metal.

\section{References}

1 G. C. Bond, "Catalysis by Metals" (Academic Press, London, 1962), Chapter 5

2 W. R. Macdonald and K. E. Hayes, F. Catalysis, 1970, 18, (1), 115

3 Ref. 1, Chapter 8

4 D. D. Eley and D. R. Rossington, in "Chemisorption", ed. W. E. Garner (Butterworths, London, 1957), p. 137. See also S. J. Holden and D. R. Rossington, F. Phys. Chem., 1964, 68, 1061

5 B. J. Wood and H. Wise, 7. Chem. Phys., 1958, 29, 1416

$6 \mathrm{~W}$. M. H. Sachtler and J. Fahrenfort, Actes $2^{\text {mo }}$ Congrès Internat. Catalyse (Editions Technip, Paris, 1962), p. 831

7 G. Parravano, 7 . Catalysis, 1970, 18, 320
8 R. S. Yolles, B. J. Wood and H. Wise, 7. Catalysis, 1971, 21, 66 and earlier references quoted therein

9 British Patent 1,152,817; U.S. Patent 3,476,808

10 French Patent 2,007,925

11 U.S. Paten $3,553,220$

12 J. G. Hardy and M. W. Roberts, 7. Chem. Soc., D, Chem. Commun., 1971, (10), 494

13 M. Boudart and L. D. Ptak, F. Catalysis, 1970, 16, 90 14 D. D. Eley, F. Res. Inst, Catalysis, Hokkaido Univ,, 1968, 16, (1), 101

15 See for example British Patent 1,243,105; W. H. Flank and H. C. Beachell, F. Catalysis, 1967, 8, (1), 316

16 British Patents 1,246,015 and 1,103,125; German Patent $1,244,766$

17 G. C. Bond and E. G. Allison, unpublished work

\section{Gold in Silver Brazing Alloys}

\section{LOW MELTING POINTS WITH INCREASED DUCTILITY}

The well-known range of quaternary alloys based upon the silver-copper-cadmium-zinc system provides the lowest melting points of any silver brazing alloys. The addition of relatively small amounts of gold to alloys of this type extends even further the range of eutectiferous alloys available, and this characteristic can be utilised to design alloys with low melting points without large contents of zinc or cadmium and therefore with enhanced ductility.

The photomicrographs show the structures of two silver brazing alloys containing respectively 12.5 and 30 per cent by weight of gold. While their melting points, both in the range 630 to $660^{\circ} \mathrm{C}$, are comparable

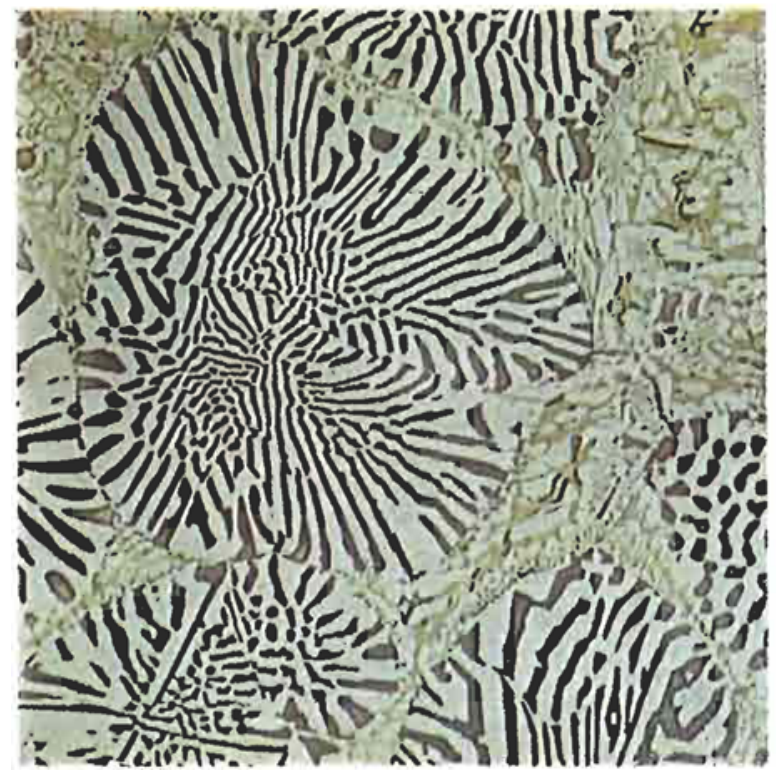

The eutectic structure of a low temperature silver braxing alloy containing 12.5 per cent gold. This has a liquidus of $660^{\circ} \mathrm{C}$ and a solidus of $630^{\circ} \mathrm{C}$ with those of the conventional quaternary silver solders the gold-bearing alloys produce joints that can readily be cold worked.

The usefulness of these alloys lies in the specialised field of composite structures in which gold is used as the surface coating or in the preparation of gold-clad base metals. In both cases the low temperatures needed to make the joints minimise the risks of surface contamination arising from either the substrate or the solder itself. They are particularly valuable when such combinations of gold and base metals must, after joining, be subjected to extensive rolling or drawing operations without annealing.

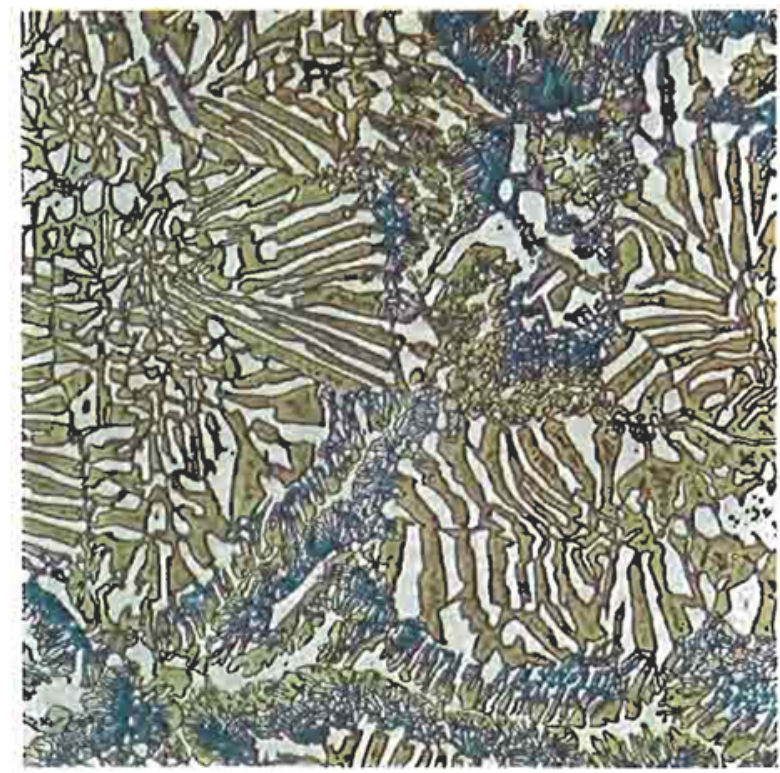

The structure of a similar alloy containing 30 per cent gold.

This also has a liquidus of $660^{\circ} \mathrm{C}$ witle a sotidus of $640^{\circ} \mathrm{C}$

$\times 125$ 